\title{
PREGNÂNCIA SIMBÓLICA VERSUS ANTEPREDICATIVO: O DIÁLOGO ENTRE MERLEAU-PONTY E CASSIRER
}

\author{
Olivier Feron \\ Universidade de Évora ${ }^{1}$
}

\section{Delimitação do campo}

Quando Merleau-Ponty aborda o problema da espacialidade e do corpo próprio na Fenomenologia da percepção, a sua reflexão representa um longo esforço para libertar a carne daquilo que ele apelida de «intelectualismo». Na sua vontade de fazer jus àquele que será o seu percurso em filosofia, e que podemos descrever tanto como uma superação de todo o tipo de idealismo (qualquer que seja o sentido do termo) como do realismo reducionista, Merleau-Ponty vai inspirar-se em larga medida nos trabalhos que Cassirer desenvolve, nomeadamente no terceiro tomo da Filosofia das formas simbólicas. Contudo esta inspiração não é pacífica: Merleau-Ponty acumula constantemente referências aos trabalhos cassirerianos visando integrar uma das dimensões mais inovadoras da reflexão cassireriana, que incide sobre aquilo a que Merleau-Ponty chama de «mundo pré-objectivo», e que na realidade constitui uma reflexão sobre o ante-predicativo. Contudo, esta convergência das análises é rapidamente contra-balançada por uma acusação sistemática a Cassirer, que é precisamente o facto de não ter conseguido escapar a um idealismo de princípio, apesar da pertinência e da originalidade das suas análises.

Aquilo que aqui está em causa é avaliar a justiça desta suspeição de um vestígio «idealista» no último dos marburgueses, quando ele procura elaborar uma genealogia das primeiras formas de constituição do sentido no próprio sensível, antes de qualquer intervenção categorial. O percurso que nos propomos aqui fazer é na realidade cruzado: só através de um método de empiètement

\footnotetext{
I Estc cstudo insere-se no projecto PTDC/FIL/71833/2006-Theories of Rationality: Neo-kanlianism and Phenomenology, financiado pela Fundação para a Ciência e a Tecnologia.
}

Phainomenon, n. ${ }^{\circ}$ 18-19, Lisboa, pp. 227-236. 
será possível avaliar as eventuais limitações do projecto cassireriano, tal como ler em relevo nas críticas merleau-pontianas o alcance da «superação» do idealismo a que se propõe o fenomenólogo francês. Isto levar-nos-á a ponderar no próprio seio da obra merleau-pontiana se a tensão que ele detecta em Cassirer não constitui o motivo que o vai levar cada vez mais longe em direcção a uma ontologie du sensible (como nos últimos textos de Le Visible et l'Invisible).

\section{A referência comum: Descartes}

O ponto de ancoragem comum a Merleau-Ponty e a Cassirer para aceder a um sensível liberto de qualquer determinação estritamente conceptual pode descrever-se pela crítica ao eterno dualismo cartesiano. É a partir da avaliação feita a Descartes que se decide efectivamente a relação que Merleau-Ponty tem com Kant via a sua crítica a Cassirer.

A análise da consciência perceptiva que Cassirer desenvolve no início do terceiro tomo da Filosofia das formas simbólicas a partir da noção fundamental de «expressão», funda-se na tradicional oposição «interior-exterior» e na tentativa da filosofia contemporânea conseguir pensar aquém desta distinção, por exemplo, nas experiências limites da "consciência» animal. Ora, sobre este ponto, Cassirer declara que estas tentativas, partindo do animal como garantia contra todo o idealismo, são votadas ao fracasso, pois falta-lhes uma dimensão essencial que se manifesta a partir da percepção humana: a reflexividade da consciência.

As diversas tentativas para alcançar e descrever a "consciência" animal já provaram que nos levavam a um impasse se tentássemos, de uma maneira ou de outra, aplicar e impor imediatamente no mundo animal a ordem complexa que estrutura a percepção humana. ${ }^{2}$

Esta reflexividade do cogito, de que Descartes assume a paternidade simbólica, é igualmente o fundamento a partir do qual a questão do ser se coloca, ${ }^{3}$

${ }^{2}$ Cassirer, E., Philosophie der symbolischen Formen III - Phänomenologie der Erkenntnis. Darmstadt: WBG, 1990, p. 74. Sublinho assinalando aqui um hegelianismo assumido por Cassirer que, por mais que ele leve a sua investigação sobre o ante-predicativo, nunca renunciará à necessidade de mediação da determinação. A ascese metodológica do behaviorismo que elimina qualquer consciência, seja ela animal como do outro, resolve o problema eliminando-o. É a razão pela qual ele distingue metafísica e teoria do conhecimento que choca contra a experiência da realidade do sujeito vivo, e «a pura fenomenologia da percepção [Phänomenologie der Wahrnemung], que só trata de si enquanto facto, enquanto quid facti, e por isso não poderia recomendar-lhe a sua via». Cassirer, E., Philosophie der symbolischen Formen III, ed. cit., p. 73.

${ }^{3}$ «Visto que a «consciência» significa para ele [Descartes], na sua essência, o acto primeiro da apreensão reflexiva do Eu por si mesmo - o acto no qual o ser do Eu se apreende e se constitui como ser do pensamento». E. Cassirer, Philosophie der symbolischen Formen III, ed. cit., pp. 74-75. 
mas coloca-se a partir daqui como sentido. Esta constituição não é a realização de uma consciência teórica soberana, mas uma experiência originária para uma consciência. Esta experiência originária expressiva, anterior a qualquer distinguo do bios theorêtikos, Cassirer estabelece-a não como fundante, mas como facto (quid facti) aquém do qual a consciência teórica não tem nenhuma possibilidade de regressar, pois esta experiência não é uma experiência de objecto, mas a modalidade primeira e originária de aparição de um sentido de ser:

Ela [a percepção] não consiste nos "elementos" da impressão sensível, mas nos caracteres expressivos originais e imediatos [...] Ela nunca se determina num simples complexo de qualidades sensíveis, mas corresponde sempre a uma tonalidade de expressão determinada e específica; ela nunca é calculada exclusivamente sobre o "quê" do objecto, mas alcança o modo da sua aparição global [...] independentemente da sua interpretação objectiva. ${ }^{4}$

Esta pré-objectividade da experiência de expressão está imersa no sentido, mas anterior a toda a interpretação porque nas "puras experiências vividas de expressão não podemos ter por guia nem o conhecimento por conceitos nem mesmo a simples linguagem. Pois ambos estão principalmente ao serviço da objectivação puramente teórica: eles edificam o mundo do logos enquanto logos pensado e falado", isto é, anterior a todos os dualismos que estruturam a teoria do conhecimento: interior-exterior, real-irreal, realidade-aparência, e evidentemente "presença autêntica - representação substitutiva". 5 A intenção cassireriana é pois reatar com o "tecido sólido" que o real é para Merleau-Ponty quando este declara que a "percepção não é uma ciência do mundo, nem tampouco um acto, uma tomada de posição deliberada, ela é o fundo sobre o qual todos os actos se separam e ela é pressuposta por eles". ${ }^{6}$ Este real não é o produto de nenhum acto de uma consciência soberana que procederia por reconstrução do que havia sido previamente dado, mas negligenciado. Uma vez que os "elementos" originários que constituiriam o material da percepção seriam eles próprios apenas o produto de uma actividade teórica e nunca um dado originário (o que parece negligenciar o empirismo na sua "ascese" que visa purificar a sua investigação de qualquer elemento "idealista"). O cepticismo contra qualquer ilusão de atomização da percepção, contra qualquer sonho de filtrar a percepção para recolher os seus últimos componentes, constitui um princípio comum assumido pelos dois filósofos, que se juntam aqui numa atitude partilhada tanto pelo neokantismo como pela fenomenologia. ${ }^{\text {? }}$

${ }^{4}$ Cassirer, E., Philosophie der symbolischen Formen III, ed. cit., p. 78.

5 Ibid., p. 79.

${ }^{6}$ Merleau-Ponty, M., Phénoménologie de la perception, Paris: Gallimard, 1990, p. v.

7 Vale lembrar aqui a importância decisiva que o artigo de Paul Natorp, intitulado "Über objektive und subjektive Begründung der Erkenntnis", de 1887, teve para Husserl no que diz respeito à superação de todo o psicologismo em fenomenologia. Cf. Husserl, E., Logischen 
A adesão à presença real no seu próprio aparecer assenta sobre uma comunidade de sim-patia que não pressupõe nenhum acto fundador, mas necessariamente uma consciência "aderente", cujo proto-fenómeno se encontra na relação que o espírito mantém com o corpo. É na espessura do corpo próprio (tanto como no de outrem) que se produz a primeira relação simbólica que nunca pode ser reduzida à categoria causal compreendida como processo de produção de sentido por inferência. Aqui, trata-se efectivamente de uma vida sempre já no sentido tal como ele se manifesta no fenómeno originário de expressão, ${ }^{8}$ Urphänomen de unidade concreta e real que se enraíza na encarnação.

Esta determinação da carne como vida primitiva no sentido não escapou. evidentemente a Merleau-Ponty que se inspira em grande medida nas análises cassirerianas na própria Fenomenologia da percepção (cujo título, lembremo-lo, já se encontra em Cassirer, e caracteriza toda a primeira parte de Filosofia das formas simbólicas). Não obstante, Merleau-Ponty não deixa de fazer pesar uma suspeição sobre a intenção que guia a filosofia das formas simbólicas, e que poderia concentrar-se à volta da questão do estatuto da consciência. Esta questão que Merleau-Ponty relaciona constantemente ao destino do suposto intelectualismo de Cassirer, situa-se a um nível que nunca deixou de preocupar os próprios intérpretes da obra do filósofo de Hamburg: a determinação de uma hipotética unidade da consciência simbólica, que pairaria sobre a variedade das modalidades da manifestação do sentido (Ausdruck-Expressão, Vortellung-Representação, reine Bedeutung-puraSignificação)através das múltiplas formas simbólicas (arte, mito, religião, ciência, linguagem, ...). Merleau-Ponty reconhece a pertinência do diagnóstico de Cassirer quando este faz da aplicação universal da categoria de causalidade à resolução da origem da aparição do sentido e do outro o principal escolho à correcta enunciação da temática.

Contudo, Merleaụ-Ponty não reconhece à distinção que Cassirer estabelece entre a comunidade no ser e a comunidade no sentido um alcance suficiente para libertá-lo do peso do intelectualismo, pois interpreta o sentido como valor, misturando Marburg e Bade, e faz desta distinção uma retirada da consciência

Untersuchungen, I, $\S 19$ e $\S 45$. The Hague: Martinus Nijhoff, 1975, p. 69 e p. 172 (trad. port.: Investigações lógicas, vol. I, trad. D. Ferrer. Lisboa: Phainomenon/Centro de Filosofia·da Universidade de Lisboa, 2005, p. 76 e p. 178); para uma análise do debate, cf. Villacañas, J.-L., Historia de la filosofia contemporânea. Madrid: Akal, p. 162 ss.

${ }^{8}$ «O puro fenómeno de expressão, o facto que uma certa aparição [Erscheinung] se dê ao mesmo tempo a reconhecer, na simples «doação» da sua visibilidade, como um ser animado a partir de dentro, mostra-nos, antes de mais e imediatamente, como a consciência apreende uma outra realidade sem sair de si. [...] Como poderíamos também conceber e derivar o fenómeno ingénuo de expressão a partir de alguma coisa que lhe seria transcendente, quando na realidade ele é o primeiro veículo que nos conduz até todo tipo de "transcendência", de consciência do real?» E. Cassirer, Philosophie der symbolischen Formen III, ed. cit., p. 108. 
para fora da ordem do ser. ${ }^{9}$ Assim sendo, Merleau-Ponty negligencia o facto de que não pode haver "saída da ordem do ser", pois o facto da encarnação expressiva faz com que tanto a existência como a vida no sentido são fenómenos sincrónicos, originais e insuperáveis. Todas as análises conceptuais e teóricas que incidem sobre os desenvolvimentos ulteriores que se apoiam sobre este solo originário,

a análise das formas conceptuais enquanto tais não pode esclarecer totalmente a diferença entre a ciência da natureza e a ciência da cultura. Devemos pelo contrário decidir-nos a procurar um ponto de apoio ainda mais profundo e entregar-nos a uma fenomenologia da percepção perguntando-nos em que medida ela pode contribuir para a solução do nosso problema.

Face ao pólo do objecto, do isto, do aliud que é regulado pela categoria de causalidade, situa-se o pólo "eu", ego, que engloba também o alter ego, o "tu", diferença que se manifesta ao nível da variação da intencionalidade e nos faz aceder a duas modalidades de mundo completamente distintas, mas contudo comuns à mesma consciência:

é incontestável e incontestado que o homem vive a realidade neste duplo aspecto. Trata-se aqui simplesmente de um facto que nenhuma teoria pode abalar ou suprimir. Porque é que a teoria tem tanta dificuldade em admiti-lo? ${ }^{10}$

A evocação aqui do quid facti do fenómeno originário de expressão faz da vida no sentido um horizonte insuperável sobre o qual vêm inscrever-se e desenvolver-se as múltiplas variedades de modulação, de enformação (Formung, Formgebung) desta mesma vida, sem que seja possível retirar-se dela para uma consideração sub specie aeternitatis. Neste sentido, não há e não pode haver posição de sobrevoo do homem face às suas próprias "em-formações" (Formung, Formgebung), pois era preciso desde já retirar-se do seu próprio corpo, ou seja, retirar-se do próprio horizonte de experiência, o mesmo que lhe permite um acesso ao ser (antes mesmo de poder colocar a questão do ser, que é apenas uma das múltiplas modalidades de acesso ao ser). Ao separar sentido e ser, ou-vida no ser e produto cultural, Merleau-Ponty apenas reintroduz no seio do simbólico o que Cassirer queria evitar a todo o custo, a saber, fazer de uma distinctio rationis o ponto de partida de uma filosofia da cultura. ${ }^{11}$

9 «A passagem consciente da ordem da existência para a ordem do valor e a inversão que permite afirmar como autónomos o sentido e o valor equivalem praticamente a uma abstracção, já que, do ponto de vista em que acabamos por nos colocar, a variedade dos fenómenos torna-se insignificante e incompreensível. Se a consciência é posta fora do ser, ela não poderia deixar-se abordar por ele, a variedade empírica das consciências não pode ser levada a sério», Merleau-Ponty, M., Phénoménologie de la perception, ed. cit., p. 145 [sublinhado por nós]

${ }^{10}$ Cassirer, E., Zur Logik der Kulturwissenschaften. Darmstadt: WBG, 1994 (cit. Logique des sciences de la culture, trad. J. Carro. Paris: CERF, 1991, p. 119).

11 Ver a crítica que Cassirer dirige a Windelband e a Rickert quando os acusa de se envolverem num círculo vicioso quando postulam um sistema geral dos valores para poder analisar as con- 
Aquém de toda a artificialidade semiótica que se arrisca a fazer cair o simbólico num puro nominalismo e na sua dialéctica de representante-representado, ${ }^{12}$ a encarnação no sentido representa o horizonte de todos os horizontes. $\mathrm{Ou}$, como o sintetiza o Prof. Orth,

O homem não está então (em 1929, na Filosofia das Formas simbólicas) só inserido nas formas simbólicas ou na cultura, a partir das quais ele se torna compreensível, [não é] um ponto de vista que se possa e deva de facto ter em conta e utilizar. Mas esta compreensão só é possível na medida em que o próprio homem é uma forma simbólica, [em. que] ele representa simplesmente o paradigma da forma simbólica. É neste sentido que Cassirer critica e interpreta a tradicional relação corpo-alma. [...] No homem enquanto forma simbólica, trata-se de um caso fundamental e elementar de um agregado para uma unidade de meio e de significação. Ele é aliás esta conexão, a que Cassirer aplica a fórmula merleau-pontiana, por assim dizer avant la lettre, de "encarnação do sentido" (Inkarnation des Sinnes, Philosophie der symbolischen Formen III, p. 109). ${ }^{13}$

\section{O integral da experiência}

Esta superação de todo o idealismo aquém da sua introdução pela consciência teórica manifesta-se igualmente ao nível da consciência temporal, ponto de decisão de toda a fenomenologia da consciência. Pois Merleau-Ponty, apesar da sua vontade repetida de subverter a instância subjectiva através do motivo do corpo próprio ou da carne, não pode fazer a economia do sujeito, sob pena de recair num empirismo psicologista cuja superação ele atribui ao seu mestre Husserl.

O meu corpo toma posse do tempo, faz existir um passado e um futuro para um presente, ele não é uma coisa, ele faz o tempo em vez do consentir. Mas todo o acto de fixação deve ser renovado, senão cai na inconsciência [...] a tomada que ele nos dá sobre um segmento de tempo, a síntese que ele efectua são elas mesmas fenómenos temporais, dissipam-se e só podem subsistir reapreendidas num novo acto ele mesmo temporal. A pretensão à objectividade de cada acto perceptivo é retomada pelo seguinte, mais uma vez frustrada e retomada de novo.

Esta temporalização da consciência perceptiva temporal faz com que o sujeito da percepção nunca seja uma subjectividade absoluta, que ele esteja destinado a tornar-se objecto para um Eu ulterior. A percepção está sempre no

dições de possibilidade de diferentes ciências. Cf. Zur Logik der Kulturwissenschaften (cit. Logique des sciences de la culture, ed. cit., pp. 115-117).

12 Cf. Plümacher, M., Wahrnemung, Repräsentation und Wissen. Edmund Husserl und Ernst Cassirers Analysen zur Sturktur des Bewußtsein. Berlin: Humboldt, 2004, p. 162.

13 Orth, E.W., Symbolische Formung zwischen Kulturologie und Kulturanthropologie, p. 8. Conferência proferida na Université Catholique de Louvain no âmbito do seminário permanente Ernst Cassirer, 1997-1998. 
mundo do "se" (on). Não é um acto pessoal pelo qual eu próprio daria um sentido novo à minha vida,

mas é o meu corpo como instância de um olhar capaz de penetrar a espessura e a riqueza do sensível sem que ele faça

actualmente a síntese do seu objecto, não porque ele o receba passivamente, à maneira empirista, mas porque a unidade do objecto aparece pelo tempo, e que o tempo escapa-se à medida que se recupera. ${ }^{14}$

Esta temporalização da consciência perceptiva serve de garantia a Merleau-Ponty para fundar definitivamente a finitude de uma subjectividade. que ele é obrigado a reintroduzir, mesmo enraizada na corporeidade, para que uma síntese possa surgir, "apesar" do sujeito, para além de toda a soberania transparente que ele atribui ao intelectualismo (i.e. o kantismo). A transferência da instância sintética da consciência-sujeito, vestígio de um cartesianismo sempre dualista em potência, para o corpo como "espessura" sensível sobre o qual repousa a continuidade do tempo não deve ocultar o facto de que a termo isso significa necessariamente reintroduzir o sujeito eliminado mais cedo, pois

não há objecto ligado sem ligação e sem sujeito, unidade sem unificação, mas toda a síntese é simultaneamente dilatada e refeita pelo tempo que, num só movimento, a põe em questão e a confirma porque ele produz um novo presente que retém o passado. A alternativa do naturado e do naturante transforma-se numa dialéctica do tempo constituído e do tempo constituinte. ${ }^{15}$

Ora é precisamente sobre a existência de uma possível dialéctica (no sentido kantiano) no próprio seio da consciência temporal que Cassirer se inclina quando põe em causa a pertinência da clássica distinção husserliana entre a morphè intencional e a camada hilética. Uma tal distinção ameaça a qualquer momento reintroduzir a oposição alma-corpo, que a encarnação do sentido devia oferecer sem pertinência.

Quando se assimila a esfera da consciência à do "sentido" com uma nitidez tão radical como Husserl, pode-se ainda conservar no interior da consciência em geral o seu carácter absoluto por oposição da matéria e da forma? Há ainda duas "camadas" das quais uma se qualificaria como puramente material? Será que, ao invés, não subsiste, no fundo da intenção sobre os actos animadores, que vivificam a matéria da sensação e sozinhos o investem de um sentido determinado, um vestígio deste dualismo que, impondo uma ruptura entre o «físico» e o «psíquico», substitui uma diferença de substância por uma correlação. ${ }^{16}$

14 Merleau-Ponty, M., Phénoménologie de la perception, ed. cit., pp. 277-278.

15 Ibid., p. 278.

${ }^{16}$ Cassirer, E., Philosophie der symbolischen Formen III, ed. cit., p. 225. 
A dúvida expressa por Cassirer, que pode alargar-se a Merleau-Ponty, é de dimensão, já que ela faz pesar sobre a oposição "matéria sem forma" - "forma sem matéria" a suspeita de um vestígio de determinação metafísica que corre o risco de invalidar o próprio projecto da fenomenologia e até mesmo de o fazer cair num empirismo mal resolvido. Aquilo que é notável é que a ironia da situação quer que os três filósofos, Cassirer primeiro, Husserl e Merleau-Ponty depois, identificaram o ponto sobre o qual se joga o transcendental. Se a fenomenologia resolve a dialéctiça forma-conteúdo (que acarreta a oposição representante-representado) cortando-a pela raiz através do carácter originário da correlação intencional, Cassirer, pelo seu lado, insiste continuamente desde 1910 na dinâmica da tessitura do sentido, animado pela função do simbólico (o que lhe permite evitar todas as contorções a que Merleau-Ponty tem de entregar-se para ultrapassar uma filosofia do sujeito no sentido clássico mantendo, ao mesmo tempo, necessariamente uma instância de síntese temporal que não pode ser senão, volens nolens... "subjectiva").

É nesta medida que a pregnância simbólica, definida como a

«maneira como um vivido de percepção, enquanto vivido sensível, encerra ao mesmo tempo um certo "sentido" não intuitivo que ele transmite a uma representação imediata e concreta. Não se trata portanto de simples dados "perceptivos" sobre os quais se enxertariam depois actos "aperceptivos" que serviriam para interpretá-los, para julgá-los e para transformá-los. Ao invés, é a própria percepção que deve à sua própria organização imanente uma espécie de "articulação" espiritual e que, tomada na sua textura interior, pertence também a uma textura determinada de sentido. Na sua plena actividade, na sua totalidade viva ela é, ao mesmo tempo, vida "no" sentido. Ela não é apenas recebida posteriormente nesta esfera, mas parece de alguma maneira nascida nela e com elạ. É este entrelaçamento, esta relatividade do fenómeno particular da percepção, dado aqui e agora, a uma totalidade de sentido característica, que serve para designar a expressão de "pregnância". ${ }^{17}$

Esta definição clássica da pregnância simbólica em Cassirer, que vai ao encontro da definição que Merleau-Ponty dava da percepção plena ${ }^{18}$ é integralmente temporal, e como tal intimamente dinamizada pela pulsão temporal que atravessa a totalidade da vida da consciência, e que se estende à totalidade do campo da experiência e é prévia a qualquer elemento singular: presença "real" contra representação, passado oposto ao futuro e ao presente, forma contra conteúdo ou sensível contra intelectualismo. Mas antes de mais isso permite a Cassirer não ficar preso à dialéctica do Sujeito - instância alternativa (se, on,

${ }^{17}$ Ibid., p. 229.

18 «Perceber no sentido pleno da palavra, que o opõe a imaginar, não é julgar, é apreender um sentido imanente ao sensível antes de todo o juizo. O fenómeno da percepção verdadeira oferece por isso uma significação inerente aos signos e cujo juízo é tão só a expressão facultativa.» Merleau-Ponty, M., Phénoménologie de la perception, ed. cit., p. 60. 
Dasein) que turva o projecto merleau-pontiano. Logo a natureza dinâmica do processo simbólico não se limita à sua disponibilidade para uma consciência que lhe preexistiria.

Este processo mostra assim uma nova linha oblíqua que a análise da consciência nunca pode reenviar para elementos "absolutos", já que é precisamente a pura relação que, comandando a construção da consciência, dela emerge como o verdadeiro a priori, o termo primeiro segundo a essência. ${ }^{19}$

Por conseguinte não há em Cassirer consciência absoluta que sobrevoaria estas produções, contrariamente ao que Merleau-Ponty deixa entender, ${ }^{20}$ consequentemente também não há necessidade de fazê-la desaparecer, enquanto vestígio de uma metafísica do sujeito cartesiano, sobre o qual a filosofia heideggeriana edificou toda a sua crítica da modernidade. Tampouco podemos aplicar à filosofia das formas simbólicas a crítica heideggeriana do primado da presença, já que a pulsação simbólica faz da integração da percepção na temporalidade da consciência um movimento de deriva perpétua, daquilo a que Cassirer chama Bezogenheit, esta situação de relatividade, de ser-em-relação -temporal e ideal-que determina todo o conteúdo da consciência.

Este privilégio da relação é o elemento determinante, que ele recupera da psicologia crítica de Paul Natorp, quando este enuncia avant la lettre o axioma de tónica derridaniana: "não é a apresentação, mas a representação que é o fenómeno originário", o que Cassirer desenvolve imediatamente:

apenas o vaivém entre "representante" e o "representado" produz um saber do eu e um saber dos objectos; ideais ou reais. Nós alcançamos aqui a pulsação autêntica da consciência, cujo segredo consiste precisamente em que cada batimento faça nela jorrar mil ligações. Não há percepção consciente que se reduza a um puro datum, cujo dado não será senão o de um reflexo: toda a percepção encerra um certo "carácter de direcção" e de mostração graças ao qual ela remete para além do seu aqui e do seu agora. Na qualidade de simples diferencial da percepção, ela não contém menos 0 integral da experiência. ${ }^{21}$

Não há à partida qualquer sobre-impressão de um sentido para um dado sensível originário, pois este só pode surgir, diferenciado e individualizado, sobre o fundo deste fluxo da consciência simbólica que a articula com um universo de sentido originário.

19 Cassirer, E., Philosophie der symbolischen Formen III, ed. cit., p. 230.

20 Merleau-Ponty, M., Phénoménologie de la perception, ed. cit., p. 270, nota.

${ }^{21}$ Cassirer, E., Philosophie der symbolischen Formen III, ed. cit., p. 230. A citação de Natorp evocada por Cassirer é retirada do Allgemeine Psychologie nach kritischer Methode. Tübingen, 1912, p. 56. 
A finalidade destas notas esparsas era mostrar quanto os caminhos, com frequência demasiado paralelos, de alguns autores neokantianos e de alguns fenomenólogos os levavam a partilhar problemáticas, conceitos e a confrontar-se com interrogações que, em muitos casos, poderiam beneficiar de uma leitura mútua mais generosa, o que teria permitido estabelecer um verdadeiro diálogo filosófico. Em grande medida, este diálogo foi rompido de forma duradoira em Davos em 1929, e uma certa inflexão da fenomenologia tornou completamente impossível qualquer interpelação mútua, que supera a simples colecção de clichés e de preconceitos. ${ }^{22}$

\section{ABSTRACT}

A fact ignored or underestimated by most of the specialist of the work and thought of Merleau-Ponty is the debt his phenomenology of perception has to Ernst Cassirer's own phenomenology. The articulation of an actual dialogue between the two thinkers is here anchored in Cassirer's concept of symbolic pregnance, which will have further development in Merleau's Phenomenology of Perception, especially in the chapter he dedicated to the concept of expression. The elements of a possible discussion between the two concepts are here presented as a fruitful basis to renew the reflection on the Lebenswelt problematic.

22 Tal como o assume Bruce Bégout, se Husserl quisesse «dar ao racionalismo uma fundação menos formal e mais intuitiva do que a filosofia crítica de Kant [...] isso obrigá-lo-ia a fixar a presença da significação em todos os estados da experiência, da temporalidade mais originária e da mais interna do sujeito com configurações sociais e históricas. Mas estas significações múltiplas e estratificadas, por causa da correlação intencional, dependem sempre mais ou menos da faculdade de elucidação e de validação do sujeito. Se os fenomenólogos que sucederam a Husserl pensaram poder constituir uma ontologia destes diversos domínios de objectos ou de dados (ontologia do ser, do mundo natural, do mundo pré-objectivo, da vida auto-afectiva, etc.), sem passar pela necessária recondução a uma instância subjectiva de clarificação, mas, pelo contrário, sacrificando esta última para poder, pensavam eles, aceder mais imediata e directamente à experiência assim purificada, o pai da fenomenologia, pelo seu lado, considerou sempre que a relação com uma subjectividade poderia por si mesma elucidar o conhecimento dando-lhe a auto-referencialidade necessária para uma verdade que se estabelece de si para si.» Cabestan, Ph. (dir), Introduction à la phénoménologie. Paris: Ellipses, 2003, pp. 34-35. 